\title{
Book review: Pamirian Crossroads: Kirghiz and Wakhi of High Asia
}

\author{
David Butz \\ Department of Geography \& Tourism Studies, Brock University, St. Catharines, L2S 3A1, Canada \\ Correspondence to: David Butz (dbutz@ brocku.ca)
}

Published: 3 November 2017

Kreutzmann, H.: Pamirian Crossroads: Kirghiz and Wakhi of High Asia, Wiesbaden, Harrassowitz Verlag, 559 pp., ISBN 978-3447104494, EUR 98.00, 2015.

This engrossing and remarkably informative volume analyses the changing implications of relations with neighbours, rulers and invaders for two cultural groups - Wakhi and Kirghiz - who together occupy the high-altitude plateaus and valleys of the so-called "Pamir Knot", where today Afghanistan, Tajikistan, China and Pakistan meet or closely approach one another, and where some version of "great game" geopolitics has been ebbing and flowing for centuries. The book's main argument is that despite the muchadvertised isolation of this so-called "roof of the world", Pamirian peoples' social, cultural and economic circumstances have been for many generations substantially shaped by ongoing exposure to wider political, economic and ideological currents. In order to develop this thesis, author Hermann Kreutzmann employs a diachronic and comparative methodology, which traces historically the social, political and economic circumstances of two distinct and interacting populations who share a relatively homogenous geoecological environment, but whose histories and present circumstances have placed them variably and differentially in relation to numerous political jurisdictions and spheres of influence. This ambitious approach allows Kreutzmann convincingly to demonstrate that the geographical and social positioning of Wakhi and Kirghiz communities simultaneously at the unstable margins of various non-Pamirian political units and metropolitan knowledge-producing enterprises, and at the centre of local, regional and global geopolitical struggles, has been central to their movement and migration patterns, settlement distribution, livelihood strategies, environmental resource use practices, social organization and cultural identities.

The volume's explanatory emphasis on relations of contact in conditions of peripherality is no longer uncommon in scholarship on Pamirian or other mountain communities (thanks in part to the author's own earlier work); therefore, what makes this book important is less the novelty of its central argument than the astonishing specificity, nuance, historical depth, and geographical and ethnographic detail Kreutzmann musters to support it. Indeed, Pamirian Crossroads is so packed with information, so extensive in its coverage, and so diligent in following empirical and analytical threads that it would not be inaccurate to describe it as a historical atlas or regional encyclopedia of Pamirian Central Asia, into which the central narrative arc described above is slowly and carefully woven. Evidently, this is the author's intention, given the book's many photos, maps, tables and diagrams, its extensive glossary and painstaking referencing of sources, and the organization of its main text into short chapters, themselves comprised of numerous brief sub-sections. The volume includes more than 130 maps, 50 of which Kreutzmann designed himself to depict various spatial distributions and flows ranging, for example, from the routes followed by imperial explorers, to the location of every permanent settlement in the Panj and Wakhan valleys, to the escape routes followed by particular groups of Wakhi and Kirghiz during specific periods of political turmoil. The remaining 70-plus maps are beautifully reproduced from reports, notes and publications prepared over the centuries by spies, explorers and surveyors, and they cover a temporal span from the late 17th century to the present. These are complemented by sketches, paintings and photographs from the same sources, as well as by photos and diagrams produced by the author over the course of his 35-year research association with the region. 
The photographs of contemporary photojournalists Monika Bulaj and Matthieu Paley are also featured.

Each of Pamirian Crossroads' more than 450 photos, maps and illustrations is carefully described in a lengthy caption that provides context, bibliographic information and, in the case of historical maps, reproduction details. Also included are numerous charts and tables, which usefully collate population, settlement, migration and other data painstakingly gleaned by the author from a variety of published sources and historical archives. Noteworthy among these are a series of tables precisely detailing hundreds of instances of "evasive migration" by Kirghiz and Wakhi groups and individuals between the late 1800s and the present - one small part of the evidence assembled to demonstrate the extent, nature and significance of Pamirian peoples' relations with outsiders over time.

The author is keenly aware that the historical materials on which the book depends are both rich sources of empirical information and ideologically freighted artifacts of competing British, Russian, Chinese and Afghan imperial knowledge-production enterprises. Accordingly, he treats his sources cautiously and reflexively, tracing the implications of explorers', spies' and administrators' cartographic and narrative representations - and the geopolitical interests behind them - for Kirghiz and Wakhi populations, without in most cases adjudicating the facticity of their accounts. In this way the book is able to show that the relations of contact with outsiders affecting these supposedly isolated communities have been discursive as well as material.

As I emphasized above, Pamirian Crossroads is densely packed with information and analysis presented in a variety of cartographic, pictorial, tabular and textual forms. Great care has been taken with each of these modes of representation, resulting in an empirically rich and beautifully designed volume: a labour of love. My only criticism of the work is that notwithstanding its rich content and elegant design, I had difficulty finding an effective way to read the book. Its central argument, developed essay-style in the main narrative, is sufficiently nuanced to deserve sustained attention, but I found myself continually distracted by the fascinating maps, tables and illustrations that populate almost every page. These contain information that supports the central narrative, but they are seldom directly referred to in the text so it is difficult to know the best (or intended) sequence in which to absorb the variety of information presented on a page or in a chapter, or over the course of the volume. Sometimes two halves of a paragraph are separated by several pages of maps or photos, which further disrupts the narrative flow. As a result the book's meta-argument is harder to discern and follow than ideally it would be. A more explicit summary of the argument in the opening chapters and occasional updates throughout the book on the progress of its development would be helpful.
An alternative reading strategy would be to treat the book like a reference work, and browse or search its contents according to purpose. This too is challenging, because figures and tables are not listed in the table of contents, and chapter and section headings are better suited for a linear or continuous reading than for targeted searching according to topic or keyword. The book's lengthy index is helpful but insufficient fully to overcome these difficulties. My worry is that this characteristic of the volume's design will encourage some readers to treat it like a coffee table book (it is beautiful enough), browsed mainly for its eye-catching and informative illustrations, rather than studied for the important argument it develops, or systematically searched for specific content. This would be a shame, because the book is a treasure, yielding new information, insights and analytical gems with the turn of every page. Its historical depth is unique among works on the Pamirs, and because Kreutzmann has visited the region many times over four decades - traversing the landscape, conducting research, educating students, and establishing close relations with inhabitants - the volume's treatment of present-day circumstances is comprehensive, authoritative, insightful, and delightfully close-to-the-ground. The book's penultimate chapter, which presents brief contemporary portraits of 10 Pamirian locations, is especially noteworthy in this regard.

Pamirian Crossroads has much to offer anyone interested in Pamirian Central Asia, including English-speaking Kirghiz and Wakhi scholars and historians, who are sure to welcome the volume as an important reference work and as a sympathetic treatment of their communities. The book is so richly illustrated that even those without English language skills will find much to engage them. Pamirian Crossroads will also make rewarding reading for a larger category of scholars concerned with the ways peripheral territories and their supposedly-isolated inhabitants are implicated in and affected by broader-scale social, economic and geo-political interests and circumstances. It is difficult to imagine a more thorough debunking of the myth of mountain community isolation than this book provides. My small complaints about readability aside, I am awed by the scope, comprehensiveness and rigour of this work, and I am eager to read its two companion volumes. One of these, entitled Wakhan Quadrangle: Exploration and Espionage During and After the Great Game has already been published; the other, focusing mainly on Gilgit-Baltistan's Hunza Valley, is in preparation. 